\title{
Skeletal muscle glucose transporter protein responses to antenatal glucocorticoids in the ovine fetus
}

\author{
Susan Gray, Barbara S Stonestreet ${ }^{1}$, Shanthie Thamotharan, \\ Grazyna B Sadowska', Molly Daood ${ }^{2}$, Jon Watchko² \\ and Sherin U Devaskar
}

Department of Pediatrics, David Geffen School of Medicine at UCLA, Los Angeles, California 90095, USA

${ }^{1}$ Department of Pediatrics, Brown University Medical School and Women and Infants' Hospital of Rhode Island, Providence, Rhode Island 02912, USA

${ }^{2}$ Department of Pediatrics, University of Pittsburgh School of Medicine and Magee-Womens Research Institute, Pittsburgh, Pennsylvania 15261, USA

(Requests for offprints should be addressed to S U Devaskar, David Geffen School of Medicine, UCLA, 10833 LeConte Avenue, MDCC B-2-375, Los Angeles, CA 90095-1752, USA)

\begin{abstract}
We investigated the effects of maternal antenatal dexamethasone (Dex) treatment given as a single course (4 doses) or multiple courses (20 doses) on fetal skeletal muscle glucose transporter (GLUT) protein concentrations at $70 \%$ of gestation (106 to 107 days with term being 145 to 150 days) in the ovine fetus. Antenatal corticosteroid administration was associated with a decrease in endogenous fetal plasma cortisol concentrations $(P<0 \cdot 05)$, fetal hyperglycemia $(P<0 \cdot 02)$ and hyperinsulinemia $(P<0 \cdot 05)$. These metabolic/hormonal changes were associated with a decrease in fetal body weight $(P<0.05)$ in the multiple course Dex group compared with the multiple course placebo group. These perturbations were associated with an increase in fetal skeletal muscle GLUT 1 concentrations that mediate basal glucose transport in the extensor digitorum lateralis and extensor digitorum longus muscles $(P<0 \cdot 05) 18 \mathrm{~h}$ after the last dose of Dex was given in the single course group.
\end{abstract}

However, in the multiple course Dex group, a small increase in GLUT 1 was observed only in the biceps femoris. In contrast, both single and multiple courses of antenatal Dex were associated with an increase in the extensor digitorum lateralis and biceps femoris muscle GLUT 4 (insulin-responsive) concentrations $(P<0 \cdot 05)$. We conclude that antenatal corticosteroids perturb fetal glucose/insulin homeostasis, which is associated with increases in fetal skeletal muscle glucose transporters to compensate for and attenuate the associated catabolic fetal state. These changes consist of an increase in proteins that mediate basal glucose transport (GLUT 1) to meet immediate energy requirements of the fetal skeletal muscle with an increase in basal insulin sensitivity (GLUT 4) to compensate for the Dex-induced catabolic state after exposure to multiple courses of Dex.

Journal of Endocrinology (2006) 189, 219-229

\section{Introduction}

Maternally administered antenatal corticosteroids have been widely used for the prevention of respiratory distress syndrome in low birth weight infants (Liggins \& Howie 1972, Doyle et al. 1986, Crowley 1995, National Institutes of Health Consensus Development Panel 1995). A single course of corticosteroids administered to women at risk of delivering prematurely decreases the incidence of respiratory distress syndrome, and of morbidity and mortality in neonates (Doyle et al. 1986, Crowley 1995, National Institutes of Health Consensus Development Panel 1995). In animal studies, antenatal corticosteroids have been shown to exert extra-pulmonary effects (Padbury et al. 1995, Berry et al. 1997) including a negative impact on fetal growth (Ikegami et al. 1997, Jobe et al. 1998). Recent evidence in animal studies suggests that when antenatal corticosteroids disrupt the fetal hormonal/metabolic milieu, there can be far-reaching implications into the postnatal period (Nyirenda et al. 1998, 2001, Gatford et al. 2000, Moss et al. 2001, Dodic et al. 2002).

Although a single course of antenatal steroids has been shown to be beneficial, it has become relatively common to administer repeated courses of synthetic corticosteroids to women at risk of early preterm birth without sufficient evidence concerning the safety or efficacy of this treatment (Pratt et al. 1999, Guinn et al. 2001, Leung et al. 2003). Therefore, a second National Institutes of Health panel was convened to present research on repeated courses of antenatal corticosteroids for fetal maturation (National Institutes of Health Consensus Statement 2000). 
They emphasized that animal studies should examine the pathophysiologic and metabolic mechanisms of the potential risks and benefits of this treatment (National Institutes of Health Consensus Statement 2000). The panel recommended administering a single course of antenatal corticosteroids to women threatening premature labor until further information was available from controlled trials (National Institutes of Health Consensus Statement 2000). Despite this recommendation, multiple course treatments are still given to pregnant women at continued or recurrent risk of premature labor (Thorp et al. 2001, Leung et al. 2003).

It has previously been shown that multiple courses of antenatal corticosteroids may impair fetal growth (Ikegami et al. 1997, Jobe et al. 1998). Corticosteroids have also been shown to have major effects on fetal glucose homeostasis resulting in long-term persistence of these changes after birth in sheep and rats (Nyirenda et al. 1998, 2001, Gatford et al. 2000, Sloboda et al. 2000, Moss et al. 2001, Gurrin et al. 2003, Kutzler et al. 2003). Prenatal corticosteroid exposure of mice resulted in programming of the fetus such that the adult progeny exhibited glucose intolerance (Nyirenda et al. 1998, 2001). In addition, repeated courses of maternal corticosteroid administration have been shown to alter fetal glucose homeostasis and hepatic enzyme activity in rats (Drake et al. 2005). Although some mechanisms by which such changes occur have been elucidated, which include an increase in corticosteroid receptors and hepatic phosphoenolpyruvate carboxykinase (PEPCK) expression (Nyirenda et al. 1998, Drake et al. 2005), other mechanisms that contribute to this phenotype remain to be determined.

In adult rats, corticosteroids increase the skeletal muscle and fat insulin responsive glucose transporter (GLUT 4) concentration (Hajduch et al. 1995, Dimitriadis et al. 1997), thereby augmenting glucose transport into these tissues (Hajduch et al. 1995, Dimitriadis et al. 1997). Repetitive corticosteroid dosing in the postnatal rat results in an increase in skeletal muscle GLUT 4 concentrations supporting an increase in insulin-responsive glucose transport (He et al. 2004). Although studies have examined the effects of corticosteroids on glucose transporters in postnatal and adult rodents, studies have not examined the impact of antenatal corticosteroids on fetal skeletal muscle glucose transporter protein concentrations (GLUT 1 and GLUT 4) in the sheep fetus, in which the impact of maternally administered corticosteroids on fetal glucose/ insulin homeostasis can be simultaneously examined. In addition, the effects of single and multiple courses of antenatal corticosteroids on fetal skeletal muscle glucose transporters have not been determined.

Glucose transporter proteins are membrane-spanning glycoproteins that transport glucose across the bilipid layers of cell membranes to fuel energy metabolism (Bell et al. 1993, Joost et al. 2002). A large proportion of insulin responsive glucose transport and utilization takes place in skeletal muscle (DeFronzo et al. 1981). Fetal skeletal muscle predominantly expresses two isoforms, GLUT 1, which is responsible for basal glucose transport, and GLUT 4, which is the insulin responsive glucose transporter (Schroeder et al. 1997, He et al. 2003). We have previously demonstrated that both these isoforms work in concert to meet the substrate requirements of this tissue in fetal sheep (Das et al. 1999, Anderson et al. 2001).

Based on this information, we hypothesized that antenatal corticosteroids result in metabolic perturbations in fetal glucose homeostasis that are associated with compensatory changes in fetal skeletal muscle glucose transporter concentrations. Further, we hypothesized that multiple courses of antenatal corticosteroids accentuate these perturbations when compared with those of a single course.

\section{Materials and Methods}

\section{Animals}

This study was conducted after approval by the Institutional Animal Care and Use Committee of Brown University and the Women and Infants' Hospital of Rhode Island and according to the National Institutes of Health Guidelines for the use of experimental animals.

\section{Animal preparation}

Ewes were assigned to one of four treatment groups. (1) Single course of dexamethasone (Dex) $(n=7)$ or (2) placebo $(n=6)$, and (3) five multiple courses of Dex $(n=9)$ or (4) placebo $(n=5)$. In the single course groups, the ewes received a $6 \mathrm{mg}$ intramuscular injection of Dex (Fujiwawa, Deerfield, IL, USA; concentration $=4 \mathrm{mg} / \mathrm{ml}$, $1.5 \mathrm{ml}$ was given to each ewe) or placebo $(0.9 \% \mathrm{NaCl})$ every $12 \mathrm{~h}$ for $48 \mathrm{~h}$ starting at 105 days of gestation. Full term gestation for the ovine fetus is 145 days of gestation. In the multiple course groups, the same treatment was started on days $75,84,91,98$, and 105 days of gestation. The dates for the initiation of treatment in the multiple course groups were selected early in gestation so that weekly treatments could be given, the fetuses would still be immature at the end of the studies and the fetuses exposed to both the single and multiple courses would be of identical gestational age at the end of the studies. The rationale for choosing this regimen (i.e. $6 \mathrm{mg}$ Dex every $12 \mathrm{~h}$ for $48 \mathrm{~h}$ ) was to use a schedule and doses of Dex similar to those recommended to enhance fetal maturation in women at risk of preterm delivery (National Institutes of Health Consensus Development Panel 1995), and to examine the effects of multiple courses of corticosteroids on skeletal muscle glucose transporter proteins in preterm fetuses.

Surgery was performed on 27 mixed breed ewes at 99-101 days of gestation under 1-2\% halothane anesthesia. 
Singleton and twin pregnancies were included. When a twin gestation was present, one fetus was catheterized and studied. Surgery was performed as previously described in detail (Stonestreet et al. 1993). Briefly, polyvinyl catheters were placed into the thoracic aorta through the brachial artery for withdrawal of blood samples and for monitoring heart rate and arterial blood pressure in the fetuses (Stonestreet et al. 1993). A femoral arterial catheter was placed in ewes. In the multiple course groups, surgery was performed at 98-99 days of gestation, after the first four treatment courses were given. The fifth and last course was started on the fourth day of recovery from surgery at 105 days of gestation.

The ewes in single and multiple course treatment groups remained in the animal care facility for different time intervals, i.e. approximately two weeks in the single and six weeks in the multiple course groups. Therefore, the two groups of ewes received different diets, because the single course groups remained on the farm for longer than the multiple course groups. In the animal care facility, the sheep were given timothy hay one flak per sheep twice a day and $680 \mathrm{~g}$ /day Coarse 14 (Blue Seal, Inc, Londonderry, $\mathrm{NH}$, USA), which contained $14 \%$ crude protein, $2 \cdot 5 \%$ crude fat, $9 \%$ crude fiber, $10 \%$ acid detergent fiber, $0.95 \%$ calcium, $0.55 \%$ phosphorus, $1 \cdot 25 \%$ salt, $0.9 \%$ potassium, $0 \cdot 4 \%$ selenium, and 4000 IU vitamin $\mathrm{A}$. On the farm, the sheep were given $1.8 \mathrm{~kg}$ hay per day and $454 \mathrm{~g}$ grain, which contained $10.5 \%$ protein, $3.4 \%$ fat, $8.7 \%$ neutral detergent fiber, $0.39 \%$ calcium, $0.42 \%$ phosphorus, and $7500 \mathrm{IU}$ vitamin per day.

\section{Experimental protocol and methodology}

The experimental protocols were performed in all fetal sheep at least 6 days after recovery from surgery. Physiological and hormonal values were measured in the ewes and fetuses to determine the hemodynamic, metabolic, and hormonal milieu in fetuses from which skeletal muscle was obtained. Mean arterial pressure was measured and plasma samples obtained via arterial catheters in fetuses and ewes under conditions of non-stress. These measurements were made with the ewes quietly standing in carts after they acclimatized to the laboratory. The plasma samples and physiological recordings were obtained $18 \mathrm{~h}$ after the last injections of dexamethasone or placebo had been given to ewes and just before skeletal muscle tissue samples were harvested at 106-107 days of gestation.

Maternal mean arterial blood pressure, amniotic fluid pressures, arterial $\mathrm{pH}$, blood gases and hematocrit values were measured as previously described (Stonestreet et al. 1993). Mean arterial blood pressure and amniotic fluid pressures were measured with pressure transducers (Model 1280 C; Hewlett-Packard) and recorded on a polygraph (Model 17758 B Series; Hewlett-Packard) for $5 \mathrm{~min}$ before skeletal muscle samples were obtained. Plasma glucose and lactate were measured on a glucose/ lactate analyzer (YSI 2300; STAT, Yellow Springs, OH, USA) and insulin concentrations were measured in duplicate using Coat-A-Count Insulin, a solid phase ${ }^{125}$ I-radioimmunoassay (DPC Inc, Los Angeles, CA, USA). The Coat-A-Count Insulin antiserum exhibits $100 \%$ cross-reactivity with insulin. The antiserum is highly specific for insulin, with very low cross-reactivity with other compounds. Cross-reactivity with pro-insulin at mid curve is approximately $40 \%$. The observed coefficients of variation for inter- and intra-assay precision were $6 \cdot 1$ and $6 \cdot 3 \%$ respectively. The lower limit of detection for this assay was $5 \mu \mathrm{IU} / \mathrm{ml}$. Total cortisol concentrations were measured in duplicate using Clinical Assays GammaCoat (DiaSorin, Stillwater, MN, USA) antiserum that exhibits $100 \%$ cross-reactivity with cortisol. The cross-reactivity with prednisone and prednisolone is $7 \cdot 6$ and $2 \cdot 3 \%$ respectively. The cross-reactivity with $11-$ deoxycortisol is $11.4 \%$. Cross-reactivities with other steroids are $1 \%$. The observed coefficients of variation for inter- and intra-assay precision were $10 \cdot 1$ and $7 \cdot 9 \%$ respectively. The lower limit of detection for this assay was $2 \mathrm{ng} / \mathrm{ml}$.

At the end of the study, the ewe was given intravenous pentobarbital $(15-20 \mathrm{mg} / \mathrm{kg})$ to achieve a surgical plane of anesthesia. A hysterotomy was performed, and the fetus was withdrawn from the uterus and decapitated. The ewe was then euthanased with an overdose of pentobarbital (100-200 mg/kg). The fetuses were weighed and tissue samples of skeletal muscle were obtained as previously described (Anderson et al. 2001). Briefly, muscles were dissected separately, immediately placed in liquid nitrogen, and stored at $-80{ }^{\circ} \mathrm{C}$ until analysis. The muscles included the extensor digitorum lateralis, gastrocnemius, extensor digitorum longus and biceps femoris.

\section{Skeletal muscle myosin heavy chain analysis}

In order to characterize the muscles in which glucose transporters were measured, myosin was extracted and the myosin heavy chain (MHC) phenotype was determined in the gastrocnemius (GC), extensor digitorum lateralis (ELA), extensor digitorum longus (ELO), and biceps femoris (BF) skeletal muscle samples as previously described (LaFramboise et al. 1991). These muscles were selected to represent a variety of lower extremity muscles consisting of purportedly glycolytic (ELA, ELO), oxidative (BF), and mixed (GC) fiber types that in the adult are important contributors to glucose homeostasis. Briefly, muscles were scissor-minced on ice in 4 volumes high-ionic strength Guba-Straub buffer $(300 \mathrm{mM} \mathrm{NaCl}$, $100 \mathrm{mM} \mathrm{NaH}{ }_{2} \mathrm{PO}_{4}, 50 \mathrm{mM} \mathrm{Na} \mathrm{HPO}_{4}, 1 \mathrm{mM}$ EDTA, $\mathrm{pH}$ 6.5). Extracts were centrifuged at $13000 \times \boldsymbol{g}$ for $30 \mathrm{~min}$ at $4{ }^{\circ} \mathrm{C}$ and the supernatants were retained. The supernatants were diluted in 9 volumes ice-cold $1 \mathrm{mM}$ EDTA and $0 \cdot 1 \% \quad \beta$-mercaptoethanol and the myosin filaments were allowed to precipitate overnight. Filaments 
Table 1 Distribution of twins/singletons and sexes by study group

\begin{tabular}{|c|c|c|c|c|}
\hline & \multicolumn{2}{|l|}{ Single course } & \multicolumn{2}{|l|}{ Multiple courses } \\
\hline & Dexamethasone & Placebo & Dexamethasone & Placebo \\
\hline Twin/singleton & $4 / 3$ & $3 / 3$ & $5 / 4$ & $3 / 2$ \\
\hline Female/male & $5 / 2$ & $2 / 4$ & $4 / 5$ & $0 / 3^{*}$ \\
\hline
\end{tabular}

*Sex was not determined in two animals.

were pelleted and resuspended in $0.5 \mathrm{M} \mathrm{NaCl}$ and $10 \mathrm{mM}$ $\mathrm{NaH}_{2} \mathrm{PO}_{4}$ and subsequently diluted in SDS sample buffer and boiled for $2 \mathrm{~min}$. Gel electrophoresis was performed using modifications (Talmadge \& Roy 1993) of a previously described method (LaFramboise et al. 1990) using $1 \mu \mathrm{g}$ of the protein extract. SDS-PAGE comprising of a $5 \%$ separating gel and a 3\% stacking gel each containing $30 \%$ glycerol was carried out for $24 \mathrm{~h}$ at $72 \mathrm{~V}$ at $4{ }^{\circ} \mathrm{C}$. The gels were either silver stained or subjected to Western blot analysis. The latter was accomplished by transferring the gels to nitrocellulose membranes overnight at $30 \mathrm{~V}$ at $4{ }^{\circ} \mathrm{C}$. Membranes were incubated overnight with the following mouse monoclonal antibodies all at a 1:100 dilution: BF-45 ( $\alpha$-embryonic) (Azzarello et al. 1987), N3.36 (adult fast oxidative IIa and neonatal isoforms) (Hughes \& Blau 1992), N2.261 (IIa fast oxidative and I slow oxidative isoforms) (Hughes et al. 1993) and RT-D9 (IIb and IIx glycolytic isoforms) (Schiaffino et al. 1989). Anti-mouse peroxidase linked secondary antibody was applied and the blots were exposed to a chemiluminescence reagent (Amersham Life Science). The chemiluminescence was captured by autoradiography over an interval to determine the optimal exposure time. The myosin heavy chain phenotype was assessed qualitatively based on the immunodetection and electrophoretic mobility of specific myosin heavy chain isoforms on Western immunoblots.

\section{Skeletal muscle glucose transporter protein analysis}

The gastrocnemius, extensor digitorum lateralis, extensor digitorum longus, and biceps femoris muscle homogenates were sonicated and centrifuged at $10000 \times \boldsymbol{g}$ at $4{ }^{\circ} \mathrm{C}$ for $10 \mathrm{~min}$ and the supernatant saved for Western blot analysis. Pre-determined optimal protein concentrations of the homogenates $(25 \mu \mathrm{g})$ were subjected to discontinuous 10\% SDS-polyacrylamide gel electrophoresis followed by electroblot transfer to nitrocellulose filters (Nytran, Schleicher \& Schuell, Keene, NH, USA). The filters were incubated for $1-2 \mathrm{~h}$ at $23^{\circ} \mathrm{C}$ with an affinity purified rabbit anti-rat GLUT 1 (1:1000 dilution) and GLUT 4 (1:500 dilution) antibodies. We previously demonstrated that these two antibodies detected ovine glucose transporter isoforms with a high specificity (Das et al. 1999, Anderson et al. 2001). The filters were treated with a peroxidase linked goat anti-rabbit IgG and exposed to a chemiluminescence reagent (Amersham Life Science). The chemiluminescence was captured by autoradiography over a predetermined optimal time interval. Uniformity in inter-lane loading was confirmed by Coomassie blue staining of the polyacrylamide gel and uniformity of transfer to the filters was confirmed by Ponceau S staining. GLUT 1 and GLUT 4 protein concentrations were assessed by quantification of the protein bands by densitometry. All samples were compared with a standard control sample on each gel. The presence of linearity between the time of autoradiographic exposure and the optical density of GLUT 1 and GLUT 4 bands was initially ensured (Thamotharan et al. 2003, 2005).

\section{Statistical analysis}

Two-way analysis of variance (ANOVA) was used to compare fetal weights, physiological, biochemical, and hormonal values among fetuses of the ewes and of the ewes treated with single or multiple Dex or placebo courses. The factors were treatment (Dex or placebo) and course frequency (single or multiple). If a significant difference was found by ANOVA, the Fisher LSD post-hoc test was used to detect specific differences among the ewes or the fetuses of the ewes treated with Dex or placebo. Specific statistically significant differences between the single and multiple course groups were not reported because, as indicated above, they remained in the animal care facility for different time intervals. If a significant difference was found by the multivariate ANOVA, a univariate ANOVA was performed to detect differences in GLUT 1 and GLUT 4 protein concentrations of specific skeletal muscle types in the fetuses of ewes treated with Dex or placebo. $P<0 \cdot 05$ was considered statistically significant. Results are expressed as means \pm S.E.M.

\section{Results}

Male or female fetuses, twins and singletons were represented in all groups (Table 1). In the multiple course placebo groups, the sex in two animals was inadvertently not recorded. Therefore, in the analysis we considered 
Table 2 Maternal and fetal body weight gestational age and mean arterial blood pressure

\begin{tabular}{|c|c|c|c|c|}
\hline & \multicolumn{2}{|l|}{ Single course } & \multicolumn{2}{|c|}{ Multiple courses } \\
\hline & $\operatorname{Dex}(n=7)$ & Placebo $(n=6)$ & $\operatorname{Dex}(n=9)$ & Placebo $(n=5)$ \\
\hline Fetal wt (g) & $1375 \pm 45$ & $1504 \pm 22(5)$ & $1165 \pm 55^{*}$ & $1361 \pm 65$ \\
\hline Gestational age (days) & $107 \pm 0 \cdot 3$ & $107 \pm 0 \cdot 3$ & $106 \pm 0 \cdot 2$ & $106 \pm 0 \cdot 4$ \\
\hline Maternal mean BP $(\mathrm{mm} \mathrm{Hg})$ & $88 \pm 2$ & $89 \pm 5$ & $89 \pm 2$ & $85 \pm 3(4)$ \\
\hline Fetal mean BP (mm Hg) & $41 \pm 4(6)$ & $38 \pm 2$ & $43 \pm 4$ & $44 \pm 3$ \\
\hline
\end{tabular}

Dex, dexamethasone; BP, blood pressure. ${ }^{*} P<0 \cdot 05$ versus the respective placebo control group.

Where values were not available for the entire group e.g. the catheter did not work or the weight or

certain measurements were inadvertently omitted, the number of animals used is shown in parentheses.

that there were no females in this group. Nonetheless, Chi square analysis did not demonstrate statistically significant differences in sex among the groups. The weight was significantly lower in fetuses of ewes exposed to multiple courses of Dex compared with placebo, but not in the single courses (Table 2). The presence of twin versus singleton gestations did not affect the relationship between fetal body weight and the single or multiple courses of Dex or placebo (ANOVA: main effects for dexamethasone versus placebo, $\mathrm{F}=8 \cdot 1, P<0 \cdot 01$, main effects for single versus multiple courses, $\mathrm{F}=9 \cdot 0, P<0 \cdot 01$, main effects for twin versus singleton gestation, $\mathrm{F}=1 \cdot 5, P=0.23)$. There were no differences in maternal or fetal blood pressure after exposure to either course of Dex when compared with the respective placebo groups (Table 2).

Maternal and fetal blood gas and hematocrit values are summarized in Table 3. Changes in maternal variables were not observed with the exception of an increase in
$\mathrm{pH}$ after exposure to single and multiple courses of Dex. The increase in maternal $\mathrm{pH}$ was not due to a change in $\mathrm{pCO}_{2}$ but was associated with an increase in base excess after treatment with Dex. In contrast to the findings in ewes, the fetuses of Dex-treated ewes exhibited a lower $\mathrm{pH}$ than those of placebo-treated ewes. The decrease in $\mathrm{pH}$ was associated with a lower base excess (resulting in a base deficit). The lower $\mathrm{pH}$ in the fetuses of Dex-treated ewes occurred in spite of a decrease in fetal $\mathrm{pCO}_{2}$. There were no changes in $\mathrm{pO}_{2}$ or changes in fetal or maternal hematocrit values.

Maternal and fetal glucose, lactate, cortisol, and insulin concentrations were taken just before the muscle samples were obtained (Table 4). Dex administration was not associated with significant changes in maternal plasma glucose concentrations but was associated with an increase in lactate levels after exposure to multiple courses but not a single course of Dex. Significant increases in maternal

Table 3 Maternal arterial blood gases and hematocrit

\begin{tabular}{|c|c|c|c|c|}
\hline & \multicolumn{2}{|l|}{ Single course } & \multicolumn{2}{|c|}{ Multiple courses } \\
\hline & $\operatorname{Dex}(n=7)$ & Placebo $(n=6)$ & $\operatorname{Dex}(n=9)$ & Placebo $(n=5)$ \\
\hline \multicolumn{5}{|l|}{ Maternal } \\
\hline $\mathrm{pH}$ & $7 \cdot 55 \pm 0.01(6)^{*}$ & $7 \cdot 49 \pm 0 \cdot 01$ & $7 \cdot 6 \pm 0 \cdot 0^{*}$ & $7 \cdot 49 \pm 0 \cdot 01(4)$ \\
\hline $\mathrm{pO}_{2}(\mathrm{~mm} \mathrm{Hg})$ & $100 \pm 2(6)$ & $99 \pm 3$ & $98 \pm 2$ & $96 \pm 1(3)$ \\
\hline $\mathrm{pCO}_{2}(\mathrm{~mm} \mathrm{Hg})$ & $33 \pm 1(6)$ & $34 \pm 1$ & $32 \pm 1$ & $34 \pm 1(3)$ \\
\hline Base excess $(\mathrm{meq} / \mathrm{l})^{\mathrm{a}}$ & $7 \cdot 4 \pm 1 \cdot 2(6)$ & $4 \cdot 4 \pm 1 \cdot 5$ & $8 \cdot 6 \pm 1 \cdot 1$ & $4 \cdot 6 \pm 1 \cdot 6(4)$ \\
\hline Hematocrit (\%) & $27 \pm 1(6)$ & $26 \pm 1$ & $25 \pm 2$ & $28 \pm 1(4)$ \\
\hline \multicolumn{5}{|l|}{ Fetal } \\
\hline $\mathrm{pH}^{\mathrm{b}}$ & $7 \cdot 33 \pm 0 \cdot 02$ & $7 \cdot 37 \pm 0 \cdot 01$ & $7 \cdot 3 \pm 0 \cdot 02$ & $7 \cdot 35 \pm 0 \cdot 03$ \\
\hline $\mathrm{pO}_{2}(\mathrm{~mm} \mathrm{Hg})$ & $28 \pm 1(6)$ & $26 \pm 1$ & $25 \pm 1$ & $24 \pm 1$ \\
\hline $\mathrm{pCO}_{2}(\mathrm{~mm} \mathrm{Hg})$ & $43 \pm 1^{*}$ & $48 \pm 1$ & $44 \pm 1^{*}$ & $48 \pm 1$ \\
\hline Base excess (meq/l) & $-2 \cdot 1 \pm 1 \cdot 7^{*}$ & $2 \cdot 4 \pm 0 \cdot 7$ & $-3 \cdot 5 \pm 1 \cdot 5^{*}$ & $0.9 \pm 1.9$ \\
\hline Hematocrit (\%) & $31 \pm 1$ & $34 \pm 1$ & $32 \pm 2$ & $36 \pm 3$ \\
\hline
\end{tabular}

Dex, dexamethasone.

${ }^{*} P<0.05$ versus the respective placebo control group. ${ }^{a} A N O V A$ : main effects for antenatal dexamethasone treatment, $\mathrm{F}=5 \cdot 3, P<0 \cdot 05$, specific group differences were not observed for maternal base exess by post hoc analysis; ${ }^{b}$ ANOVA: main effects for antenatal dexamethasone treatment, $F=5 \cdot 8$, $P<0 \cdot 05$, specific group differences were not observed for fetal $\mathrm{pH}$ by post hoc analysis.

Where values were not available for the entire group e.g. the catheter did not work or certain

measurements were inadvertently omitted, the number of animals used is shown in parentheses. 
Table 4 Maternal and fetal plasma glucose, lactate, insulin and cortisol concentrations

\begin{tabular}{|c|c|c|c|c|}
\hline & \multicolumn{2}{|l|}{ Single course } & \multicolumn{2}{|c|}{ Multiple courses } \\
\hline & $\operatorname{Dex}(n=7)$ & Placebo $(n=6)$ & $\operatorname{Dex}(n=9)$ & Placebo $(n=5)$ \\
\hline \multicolumn{5}{|l|}{ Maternal } \\
\hline Lactate $(\mathrm{mg} / \mathrm{dl})$ & $8 \cdot 0 \pm 1 \cdot 0(6)$ & $6 \pm 1$ & $11 \cdot 0 \pm 1 \cdot 0^{*}$ & $4 \cdot 0 \pm 0 \cdot 4(4)$ \\
\hline Insulin $(\mu \mathrm{IU} / \mathrm{ml})$ & $40 \pm 9(6)^{*}$ & $17 \pm 3$ & $38 \pm 5(8)^{*}$ & $17 \cdot 4 \pm 6(4)$ \\
\hline Cortisol (ng/ml) & $5 \cdot 8 \pm 0 \cdot 4(6)^{*}$ & $38 \pm 12$ & $6 \cdot 3 \pm 0 \cdot 8$ & $23 \pm 11(4)$ \\
\hline Lactate $(\mathrm{mg} / \mathrm{dl})$ & $10 \pm 1$ & $10 \cdot 0 \pm 0 \cdot 4$ & $11 \pm 1$ & $8 \pm 1$ \\
\hline Insulin $(\mu \mathrm{IU} / \mathrm{ml})$ & $15 \cdot 1 \pm 2 \cdot 3(5)^{*}$ & $9 \cdot 5 \pm 1 \cdot 1$ & $14 \cdot 4 \pm 1 \cdot 3(8)^{*}$ & $8 \cdot 7 \pm 1 \cdot 4$ \\
\hline Insulin-to-glucose ratio ( $\mu \mathrm{IU}$ insulin/mg glucose) & $28 \cdot 0 \pm 7 \cdot 3(5)$ & $28 \cdot 0 \pm 5 \cdot 7$ & $32 \cdot 0 \pm 5 \cdot 9(8)$ & $30 \cdot 0 \pm 2 \cdot 1$ \\
\hline Cortisol $(\mathrm{ng} / \mathrm{ml})$ & $6 \cdot 1 \pm 0 \cdot 25^{*}$ & $8 \cdot 3 \pm 0 \cdot 84$ & $7 \cdot 2 \pm 0 \cdot 29$ & $7 \cdot 8 \pm 0 \cdot 7$ \\
\hline
\end{tabular}

Dex, dexamethasone. ${ }^{*} P<0 \cdot 05$ versus the respective placebo group.

Where values were not available for the entire group e.g. the catheter malfunctioned or certain measurements were inadvertently omitted, the number of animals used is shown in parentheses.

plasma insulin concentrations were observed after both single and multiple courses of Dex, and a significant decrease in plasma cortisol concentrations was seen after single, but not multiple courses of Dex $(P<0 \cdot 05)$. The fetal plasma glucose and insulin concentrations increased due to maternal Dex administration in both single and multiple course groups $(P<0 \cdot 05)$. However, the insulinto-glucose ratios did not differ among the groups of fetal sheep. Endogenous fetal plasma cortisol concentrations were lower in fetuses of Dex-treated ewes in the single course group $(P<0 \cdot 05)$.

In order to characterize the type of fetal sheep muscles in which we examined the glucose transporter concentrations, Western immunoblot analysis was performed for skeletal muscle myosin heavy chains in fetal and adult sheep. The myosin heavy chain phenotype of fetal and adult muscles (Fig. 1) was notable for the absence of embryonic, and glycolytic IIb and IIx MHC isoforms, and for the presence of abundant oxidative MHC IIa and I isoform expression. No major differences were detected between fetal and adult skeletal muscles or across muscle groups. Maternal exposure to a single course of Dex was associated with a significant increase in GLUT 1 concentrations in the ELA and ELO muscles with no change in GC and BF muscles when compared with the respective placebo group (Fig. 2A). In contrast, maternal treatment with multiple courses of Dex was not associated with significant changes in GLUT 1 concentrations, except for a small but significant increase in GLUT 1 concentrations in the BF when compared with the respective placebo group. Maternal treatment with both single and multiple Dex courses was associated with increases in skeletal muscle GLUT 4 concentrations in the ELA and BF muscles when compared with the respective placebo treatment groups (Fig. 2B). Changes were not observed in the GC or ELO muscles.

\section{Discussion}

The dexamethasone regimen that we used was based on recommendations for fetal maturation in pregnant women with premature labor (National Institutes of Health Consensus Development Panel 1995). The ewes were given a standard $6 \mathrm{mg}$ dose of Dex that was not adjusted for the weight of the ewes or for the number of fetuses present. This treatment protocol is similar to current practice for pregnant women in premature labor that also does not adjust for maternal weight or fetal number (National Institutes of Health Consensus Development Panel 1995).

We have shown that antenatal Dex suppressed maternal and fetal endogenous cortisol concentrations at $70 \%$ of gestation (106 to 107 days with term being 145 to 150 days). The single course but not the multiple courses of corticosteroids appeared to have suppressed the fetal hypothalamic-pituitary-adrenal axis. These findings could imply that the hypothalamic-pituitary-adrenal axis may have been reset after repeated corticosteroid exposure, whereby the negative feedback loop may have been attenuated (Seckl et al. 1995, Seckl \& Miller 1997). Alternatively, the lack of change in plasma cortisol concentration after exposure to the multiple courses of Dex could reflect potential down regulation of central glucocorticoid receptors (Felszeghy et al. 1996). We did not measure fetal adrenocorticotrophin levels or glucocorticoid receptors, hence definitive conclusions regarding mechanisms behind the reductions in fetal plasma cortisol concentrations after the single, but not multiple courses of Dex await further study. We also cannot rule out the possibility that the lack of change in plasma cortisol concentration after multiple courses of Dex could be secondary to initiating treatment early in gestation. Although maternal basal glucose concentrations were not 
Embryonic isoform

BF-FSP BF-A ELA-FSPELA-A GC-FMP GC-A ELO-FMP ELO-A
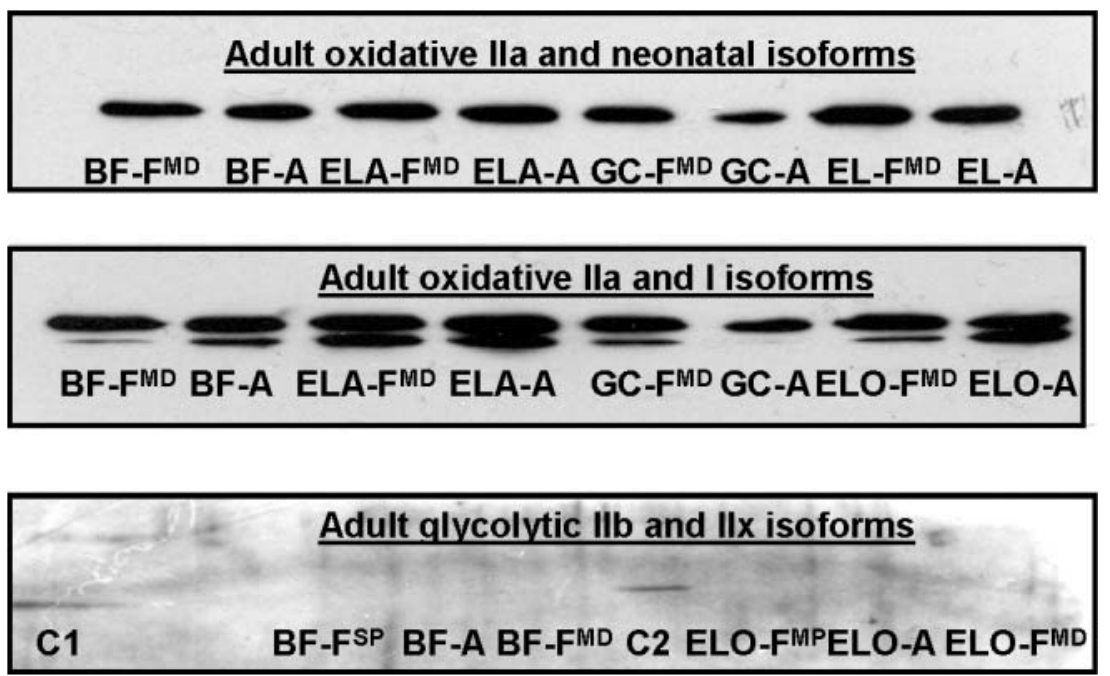

Figure 1 Myosin heavy chain isoform characterization by Western blot analysis. Representative Western immunoblots of biceps femoris (BF), extensor digitorum lateralis (ELA), gastrocnemius (GC), and extensor digitorum longus (ELO) muscles obtained from fetal (F) groups that received either placebo $\left({ }^{\mathrm{P}}\right)$ or Dex $\left({ }^{\mathrm{D}}\right)$ as single $\left({ }^{\mathrm{S}}\right)$ or multiple $\left({ }^{\mathrm{M}}\right)$ courses, and the untreated adult control (A), demonstrating the absence of embryonic myosin heavy chain isoform using BF-45 antibody (A), a single fast MHC isoform using the N3.36 antibody (B), type I (slow, oxidative) and type lla (fast, oxidative) myosin heavy chain isoforms using the N2.261 antibody (C), and the absence of type Ilb and IIx glycolytic myosin heavy chain protein bands using the RT-D9 antibody (D). The adult rat external abdominal oblique muscle designated as $\mathrm{C} 1$ and the costal diaphragm muscle designated as C2 served as positive controls for IIb and IIx expression respectively in (D). affected, Dex treatment caused hyperinsulinemia in ewes. Maternal hyperinsulinemia was associated with metabolic alkalosis. In contrast, the fetus demonstrated hyperglycemia, hyperinsulinemia, and small reductions in $\mathrm{pH}$ that were associated with metabolic acidosis, despite reductions in $\mathrm{pCO}_{2}$. Hyperinsulinemia in the sheep fetus and newborn human infant has been associated with metabolic acidosis because of increased oxygen consumption (Hay \& Meznarich 1986, Thorp et al. 2001).

This perturbation in the fetal metabolic milieu may be related to Dex-induced changes in hepatic and/or PEPCK enzyme concentrations, thereby setting the stage for persistent glucose intolerance (Nyirenda et al. 1998, 2001). Fetal hyperglycemia resulted in hyperinsulinemia in our study, which, in turn, increased skeletal muscle GLUT 1 concentrations in extensor digitorum lateralis, extensor digitorum longus, and biceps femoris muscles. Similarly, an increase in GLUT 4 concentrations of the extensor digitorum lateralis and biceps femoris muscles was observed. Although the changes in GLUT concentrations that we observed were not large, previous work by some of us has demonstrated that even small changes in
GLUT concentrations in the ovine fetus can have a major impact on fetal glucose homeostasis (Anderson et al. 2005).

Previous investigations by some of us (Anderson et al. 2001) revealed that hyperglycemia in the presence of normoinsulinemia results in an acute increase in skeletal muscle GLUT 1 concentrations. On the other hand, hyperinsulinemia in the presence of euglycemia increases GLUT 4 concentrations (Anderson et al. 2001). These changes occur shortly after the onset of glucose or insulin infusions (Anderson et al. 2001). Our findings in the present study were similar, because within $18 \mathrm{~h}$ after the last dose of Dex was administered in the single course, but not in the multiple course group, hyperglycemia was associated with an increase in GLUT 1 concentrations. In addition, some of us (Das et al. 1999) have shown that chronic hyperglycemia results in down regulation of GLUT 1 in fetal skeletal muscle. Consistent with these findings (Das et al. 1999), the multiple courses of Dex, which most likely were associated with frequent intermittent elevations in fetal glucose concentrations, were not associated with an increase in GLUT 1 concentrations, except for a small increase in the biceps femoris muscle. 
(A)

\section{FETAL SKELETAL MUSCLE - GLUT 1}

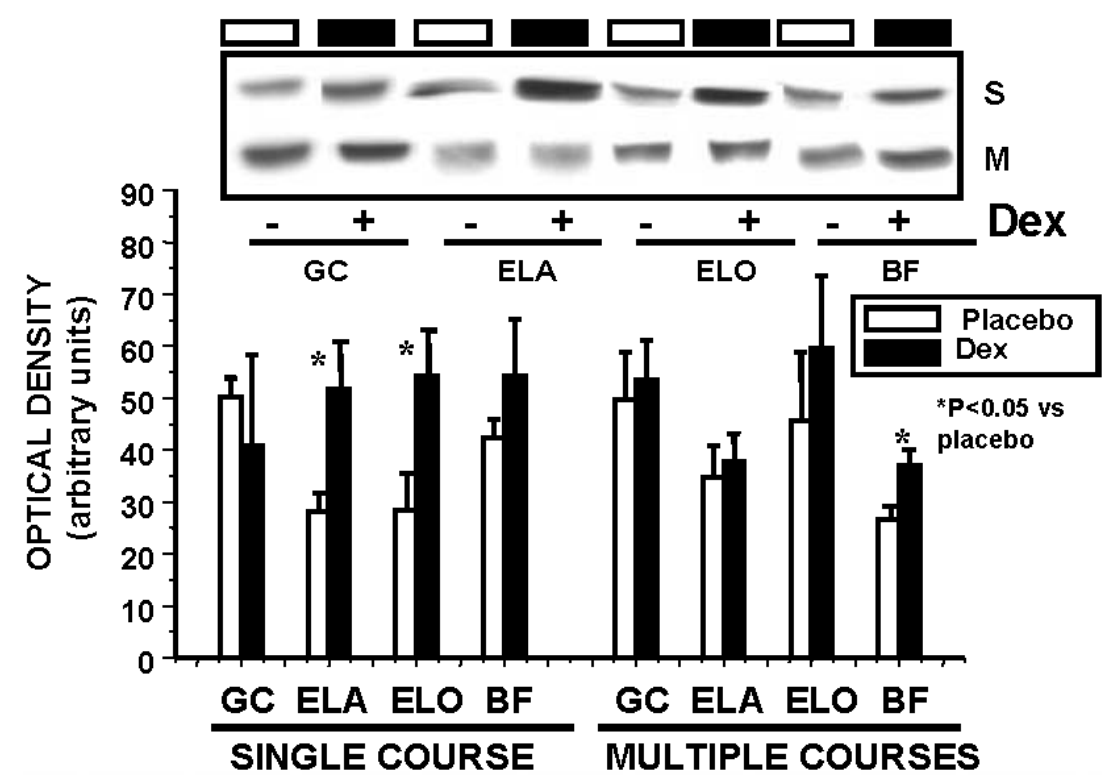

(B)

FETAL SKELETAL MUSCLE - GLUT 4

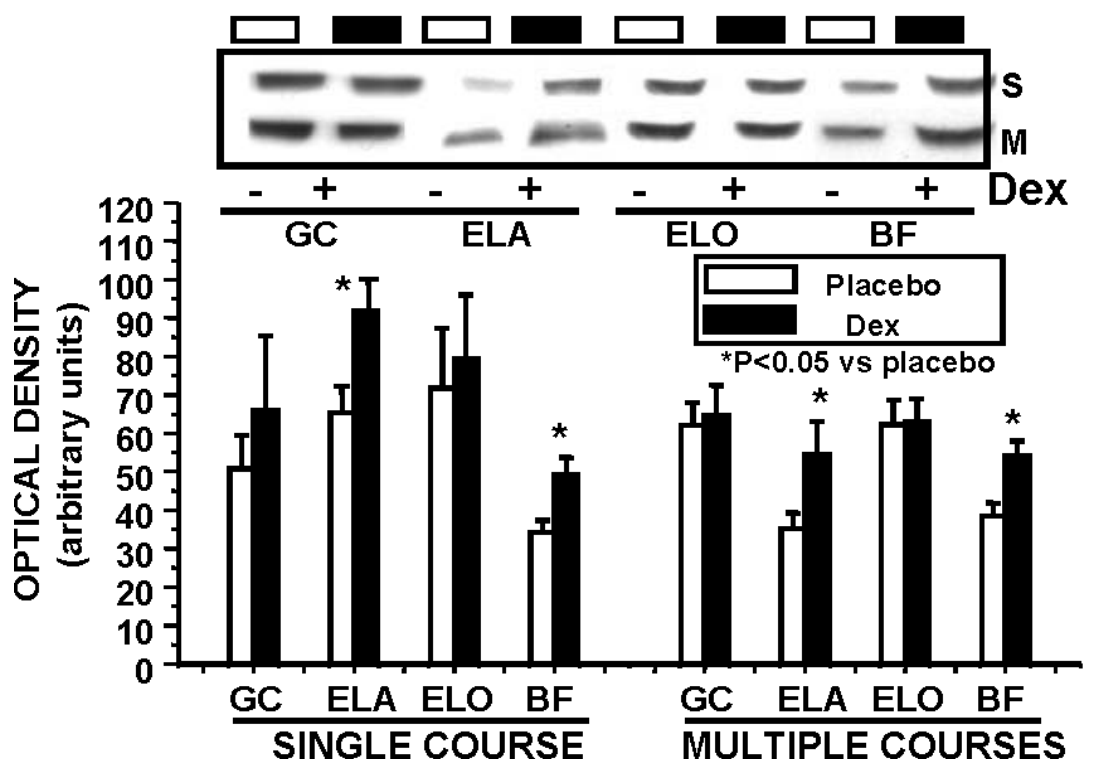

Figure 2 Glucose transporter protein studies. (A) GLUT 1 protein. Representative Western blot analysis (upper panel) and the respective semi-quantitative analysis (lower panel) of fetal GLUT 1 protein concentrations in gastrocnemius (GC), extensor digitorum lateralis (ELA), extensor digitorum longus (ELO), and biceps femoris (BF) muscles following antenatal dexamethasone (Dex; +) or placebo $(-)$ administration consisting of a single (S) or multiple (M) courses. In single course groups, $n=7$ for Dex and $n=6$ for placebo; in multiple course groups, $n=9$ for Dex and $n=5$ for placebo. ${ }^{\star} P<0 \cdot 05$ compared with respective placebo group. (B) GLUT 4 protein. Representative Western blot analysis (upper panel) and the respective semi-quantitative analysis (lower panel) of fetal GLUT 4 protein concentrations in gastrocnemius (GC), extensor digitorum lateralis (ELA), extensor digitorum longus (ELO), and biceps femoris (BF) muscles following antenatal dexamethasone (Dex; +) or placebo (-) administration consisting of a single $(S)$ or multiple $(M)$ courses. In single course groups, $n=7$ for Dex and $n=6$ for placebo; in multiple course groups, $n=9$ for Dex and $n=5$ for placebo. ${ }^{*} P<0 \cdot 05$ compared with respective placebo group. 
Therefore, differences between the effects of single and multiple courses of Dex on fetal GLUT 1 concentrations are most likely related to a potentially greater exposure to intermittent elevations in fetal glucose concentrations resulting from maternal treatment with multiple courses of Dex.

Hyperinsulinemia was present to a similar extent in fetuses after maternal exposure to both single and multiple courses of Dex. These fetal elevations in insulin concentrations were associated with significant increases in the insulin responsive glucose transporter isoform GLUT 4 concentrations after both Dex regimens (Schroeder et al. 1997, He et al. 2003). When hyperglycemia is associated with an acute increase in fetal skeletal muscle GLUT 1 concentrations, there is an increase in basal glucose utilization (Anderson et al. 2001), whereas a hyperinsulinemia-related increase in fetal skeletal muscle GLUT 4 concentrations results in an insulin-induced increase in glucose utilization (Anderson et al. 2001).

The glucose transporter changes that we observed were limited to two or three muscle types. Inter-muscle fiber type differences were not the reason for the observed muscle group specific changes, because the fast (IIa) and slow oxidative (I) myosin heavy chains were noted in all fetal muscle groups and were similar to those in adult muscle, although the glycolytic IIb and IIx isoforms were absent. The reason for these observed changes in some but not all muscles examined cannot be determined by our study, but may relate either to differences in inter-muscle glucose utilization patterns or to glucocorticoid receptor distribution. The pattern of myosin heavy chain expression in fetal sheep skeletal muscle confirms that muscle development in fetal sheep is more mature and adult-like when compared with rodents (Azzarello et al. 1987, Anderson et al. 2001). The absence in sheep fetal muscle of the $\alpha$-embryonic MHC isoform that is present in the rat fetus, along with the demonstration of fast and slow oxidative MHC isoforms (types IIa and I) found in adult sheep and rodents supports this premise (Hughes \& Blau 1992, Hughes et al. 1993). The absence of glycolytic isoforms (types IIb and IIx) in fetal sheep that are present in adult rodent muscle demonstrates that the muscle groups we examined were primarily oxidative. Oxidative muscle in the adult rodent is known to be insulin responsive and expresses large amounts of GLUT 4 (Rodnick et al. 1992a, 1992b).

The increase in fetal skeletal muscle GLUT 1 and GLUT 4 concentrations is similar to our previous observation of a Dex-induced increase in postnatal rat skeletal muscle GLUT 4 concentrations (He et al. 2004). In our present study, GLUT 1 and GLUT 4 changes occurred in the presence of a Dex-induced reduction in fetal weight. Fetal weight was reduced after exposure to multiple, but not to a single course of Dex. However, a catabolic state may have been present after exposure to both the single and multiple course regimens as Dex treatment of ewes was associated with a relative decrease in fetal $\mathrm{pH}$ in the single course Dex-treated group. In the presence of a catabolic state, the increase in fetal skeletal muscle GLUT 1 and GLUT 4 concentrations most likely reflects a compensatory response to increase substrate availability/ utilization and heightened fetal insulin sensitivity. However, in previous work when fetal growth restriction resulted from nutrient restriction as a consequence of maternal insulin infusions with maternal hypoglycemia, fetal hypoglycemia and fetal hypoinsulinemia, fetal skeletal muscle GLUT 1 and GLUT 4 concentrations did not change (Das et al. 1999). Similarly, changes were not observed in skeletal muscle of fetal rats exposed to antenatal dexamethasone (Cleasby et al. 2003). In this latter study, the whole hind limb was examined rather than specific muscle types. This may have resulted in a diluting effect that could have negated detectable changes in glucose transporters (Cleasby et al. 2003). It is likely that we detected Dex-induced changes in fetal skeletal muscle glucose transporters because we examined specific hind limb muscle types separately. Thus, fetal hyperinsulinemia secondary to Dex-induced hyperglycemia increased fetal skeletal muscle GLUT 1 and GLUT 4 concentrations in a muscle-specific manner, which, in turn, partially compensated for and supplied energy to the catabolic fetal skeletal muscle.

There are several possible limitations to our study. There were differences between the single and multiple course groups in animal husbandry and the time of surgery relative to when skeletal muscle tissue was harvested, the groups contained both twin and singleton fetuses, and both male and female fetuses. A recent report emphasizes the importance of differentiating between singleton and twin pregnancies because basal adrenocortical function as well as adrenocortical responsiveness appears to be blunted in twin relative to singleton fetuses (Gardner et al. 2004). We were not able to study a sufficient number of animals to differentiate the effects of these variables on the outcome measures of our study. Factors such as inclusion of twins and singletons, and fetuses of both sexes most likely would have increased the variability of our data. In spite of these potential confounding variables, we did identify increases in fetal GLUT 1 and GLUT 4 expression after maternal dexamethasone treatment. Nonetheless, we cannot rule out the possibility that differences in animal husbandry, and the twin and sex distribution could have influenced our results with regard to the apparent variability in the single and multiple course groups.

We conclude that fetal exposure to corticosteroids caused fetal hyperglycemia and hyperinsulinemia. These perturbations in the fetal metabolic/hormonal milieu were associated with an increase in fetal skeletal muscle GLUT 1 and GLUT 4 concentrations. We speculate that increases in glucose transporter concentrations augmented fetal skeletal muscle glucose uptake/utilization. Despite these increases in transporter protein concentrations 
known to mediate fetal skeletal muscle glucose transport (Anderson et al. 2001, Koenen et al. 2002), antenatal corticosteroids were associated with fetal growth restriction related to mechanisms other than glucose transport (Hasselgren 1999). This fetal phenotype is suggestive of a catabolic state due to antenatal corticosteroid administration whether single or multiple courses were administered. Thus, a single course of antenatal corticosteroids was adequate to bring about these metabolic changes in the developing fetus. These fetal changes may set the stage for future development of persistent metabolic derangements resulting in an altered adult phenotype. A recent follow-up study in humans 30 years after treatment with a single course of antenatal betamethasone has demonstrated higher plasma insulin concentrations after exposure to an oral glucose tolerance test suggesting that antenatal exposure to betamethasone may result in insulin resistance in the adult offspring (Dalziel et al. 2005). The changes in fetal glucose homeostasis and GLUT 1 and GLUT 4 transporters that we observed after exposure to antenatal Dex may begin to define some of the early fetal events that could have preceded and persisted in a similar manner to the changes recently reported in the human adult 30 years after being exposed to antenatal corticosteroids as fetuses (Dalziel et al. 2005).

\section{Funding}

This work was supported by grants from the National Institutes of Health, HD 41230 (S U D), HD 25024 (S U D) and HD 34618 (B S S).

\section{Acknowledgements}

Antibodies used for the myosin studies were gifts from S Schiaffino (University of Padua, Padua, Italy) and H Blau (Stanford University, Palo Alto, CA, USA). We thank Stephanie Newton for her assistance in data analysis. The authors declare that there is no conflict of interest that would prejudice the impartiality of this scientific work.

\section{References}

Anderson MS, He J, Flowers-Ziegler J, Devaskar SU \& Hay WW Jr 2001 Effects of selective hyperglycemia and hyperinsulinemia on glucose transporters in fetal ovine skeletal muscle. American Journal of Physiology. Regulatory, Integrative and Comparative Physiology 281 R1256-R1263.

Anderson MS, Thamotharan M, Kao D, Devaskar SU, Qiao L, Friedman JE \& Hay WW Jr 2005 Effects of acute hyperinsulinemia on insulin signal transduction and glucose transporters in ovine fetal skeletal muscle. American Journal of Physiology. Regulatory, Integrative and Comparative Physiology 288 R 473-R481.

Azzarello G, Sartore S, Saggin L, Gorza L, D'Andrea E, Chieco-Bianchi L \& Schiaffino S 1987 Myosin isoform expression in rat rhabdomyosarcoma induced by Moloney murine sarcoma virus. Journal of Cancer Research Clinical Oncology 113 417-429.

Bell GI, Burant CF, Takeda J \& Gould GW 1993 Structure and function of mammalian facilitative sugar transporters. Journal of Biological Chemistry 268 19161-19164.

Berry LM, Polk DH, Ikegami M, Jobe AH, Padbury JF \& Ervin MG 1997 Preterm newborn lamb renal and cardiovascular responses after fetal or maternal antenatal betamethasone. American Journal of Physiology 272 R1972-R1979.

Cleasby ME, Kelly PA, Walker BR \& Seckl JR 2003 Programming of rat muscle and fat metabolism by in utero overexposure to glucocorticoids. Endocrinology 144 999-1007.

Crowley PA 1995 Antenatal corticosteroid therapy: a meta-analysis of the randomized trials, 1972 to 1994. American Journal of Obstetics and Gynecology 173 322-335.

Dalziel SR, Walker NK, Parag V, Mantell C, Rea HH, Rodgers A \& Harding JE 2005 Cardiovascular risk factors after antenatal exposure to betamethasone: 30 -year follow-up of a randomised controlled trial. Lancet 365 1856-1862.

Das UG, Schroeder RE, Hay WW Jr \& Devaskar SU 1999 Time-dependent and tissue-specific effects of circulating glucose on fetal ovine glucose transporters. American Journal of Physiology 276 R809-R817.

DeFronzo RA, Jacot E, Jequier E, Maeder E, Wahren J \& Felber JP 1981 The effect of insulin on the disposal of intravenous glucose. Results from indirect calorimetry and hepatic and femoral venous catheterization. Diabetes 30 1000-1007.

Dimitriadis G, Leighton B, Parry-Billings M, Sasson S, Young M, Krause U, Bevan S, Piva T, Wegener G \& Newsholme EA 1997 Effects of glucocorticoid excess on the sensitivity of glucose transport and metabolism to insulin in rat skeletal muscle. Biochemical Journal 321 707-712.

Dodic M, Abouantoun T, O'Connor A, Wintour EM \& Moritz KM 2002 Programming effects of short prenatal exposure to dexamethasone in sheep. Hypertension 40 729-734.

Doyle LW, Kitchen WH, Ford GW, Rickards AL, Lissenden JV \& Ryan MM 1986 Effects of antenatal steroid therapy on mortality and morbidity in very low birth weight infants. Journal of Pediatrics 108 287-292.

Drake AJ, Walker BR \& Seckl JR 2005 Intergenerational consequences of fetal programming by in utero exposure to glucocorticoids in rats. American Journal of Physiology. Regulatory, Integrative and Comparative Physiology 288 R34-R38.

Felszeghy K, Gaspar E \& Nyakas C 1996 Long-term selective down-regulation of brain glucocorticoid receptors after neonatal dexamethasone treatment in rats. Journal of Neuroendocrinology 8 493-499.

Gardner DS, Jamall E, Fletcher AJ, Fowden AL \& Giussani DA 2004 Adrenocortical responsiveness is blunted in twin relative to singleton ovine fetuses. Journal of Physiology 557 1021-1032.

Gatford KL, Wintour EM, De Blasio MJ, Owens JA \& Dodic M 2000 Differential timing for programming of glucose homoeostasis, sensitivity to insulin and blood pressure by in utero exposure to dexamethasone in sheep. Clinical Science 98 553-560.

Guinn DA, Atkinson MW, Sullivan L, Lee M, MacGregor S, Parilla BV, Davies J, Hanlon-Lundberg K, Simpson L, Stone J et al. 2001 Single vs weekly courses of antenatal corticosteroids for women at risk of preterm delivery: a randomized controlled trial. Journal of the American Medical Association 286 1581-1587.

Gurrin LC, Moss TJ, Sloboda DM, Hazelton ML, Challis JR \& Newnham JP 2003 Using WinBUGS to fit nonlinear mixed models with an application to pharmacokinetic modelling of insulin response to glucose challenge in sheep exposed antenatally to glucocorticoids. Journal of Biopharmacological Statistics 13 117-139.

Hajduch E, Hainault I, Meunier C, Jardel C, Hainque B, Guerre-Millo M \& Lavau M 1995 Regulation of glucose 
transporters in cultured rat adipocytes: synergistic effect of insulin and dexamethasone on GLUT 4 gene expression through promoter activation. Endocrinology 136 4782-4789.

Hasselgren PO 1999 Glucocorticoids and muscle catabolism. Current Opinions in Clinical Nutrition and Metabolic Care 2 201-205.

Hay WW Jr \& Meznarich HK 1986 The effect of hyperinsulinaemia on glucose utilization and oxidation and on oxygen consumption in the fetal lamb. Quarterly Journal of Experimental Physiology 71 689-698.

He J, Thamotharan M \& Devaskar SU 2003 Insulin-induced translocation of facilitative glucose transporters in fetal/neonatal rat skeletal muscle. American Journal of Physiology. Regulatory, Integrative and Comparative Physiology 284 R1138-R1146.

He J, Varma A, Weissfeld LA \& Devaskar SU 2004 Postnatal glucocorticoid exposure alters the adult phenotype. American Journal of Physiology. Regulatory, Integrative and Comparative Physiology 287 R198-R208.

Hughes SM \& Blau HM 1992 Muscle fiber pattern is independent of cell lineage in postnatal rodent development. Cell 68 659-671.

Hughes SM, Cho M, Karsch-Mizrachi I, Travis M, Silberstein L, Leinwand LA \& Blau HM 1993 Three slow myosin heavy chains sequentially expressed in developing mammalian skeletal muscle. Developmental Biology 158 183-199.

Ikegami M, Jobe AH, Newnham J, Polk DH, Willet KE \& Sly P 1997 Repetitive prenatal glucocorticoids improve lung function and decrease growth in preterm lambs. American Journal of Respiratory and Critical Care Medicine 156 178-184.

Jobe AH, Newnham J, Willet K, Sly P \& Ikegami M 1998 Fetal versus maternal and gestational age effects of repetitive antenatal glucocorticoids. Pediatrics 102 1116-1125.

Joost HG, Bell GI, Best JD, Birnbaum MJ, Charron MJ, Chen YT, Doege H, James DE, Lodish HF, Moley KH et al. 2002 Nomenclature of the GLUT/SLC2A family of sugar/polyol transport facilitators. American Journal of Physiology Endocrinology and Metabolism 282 E974-E976.

Koenen SV, Mecenas CA, Smith GS, Jenkins S \& Nathanielsz PW 2002 Effects of maternal betamethasone administration on fetal and maternal blood pressure and heart rate in the baboon at 0.7 of gestation. American Journal of Obstetics and Gynecology 186 812-817.

Kutzler MA, Molnar J, Schlafer DH, Kuc RE, Davenport AP \& Nathanielsz PW 2003 Maternal dexamethasone increases endothelin-1 sensitivity and endothelin A receptor expression in ovine foetal placental arteries. Placenta 24 392-402.

LaFramboise WA, Daood MJ, Guthrie RD, Moretti P, Schiaffino S \& Ontell M 1990 Electrophoretic separation and immunological identification of type IIx myosin heavy chain in rat skeletal muscle Biochimica et Biophysica Acta 1035 109-112.

LaFramboise WA, Daood MJ, Guthrie RD, Schiaffino S, Moretti P, Brozanski B, Ontell MP, Butler-Browne GS, Whalen RG \& Ontell M 1991 Emergence of the mature myosin phenotype in the rat diaphragm muscle. Developmental Biology 144 1-15.

Leung TN, Lam PM, Ng PC \& Lau TK 2003 Repeated courses of antenatal corticosteroids: is it justified? Acta Obstetrica et Gynecologica Scandinavica 82 589-596.

Liggins GC \& Howie RN 1972 A controlled trial of antepartum glucocorticoid treatment for prevention of the respiratory distress syndrome in premature infants. Pediatrics 50 515-525.

Moss TJ, Sloboda DM, Gurrin LC, Harding R, Challis JR \& Newnham JP 2001 Programming effects in sheep of prenatal growth restriction and glucocorticoid exposure. American Journal of Physiology. Regulatory, Integrative and Comparative Physiology 281 R960-R970.

National Institutes of Health Consensus Development Panel 1995 Effect of corticosteroids for fetal maturation on perinatal outcomes. Journal of the American Medical Association 273 413-418.
National Institutes of Health Consensus Statement 2000 Antenatal corticosteroids revisited: repeat courses. 17 1-18.

Nyirenda MJ, Lindsay RS, Kenyon CJ, Burchell A \& Seckl JR 1998 Glucocorticoid exposure in late gestation permanently programs rat hepatic phosphoenolpyruvate carboxykinase and glucocorticoid receptor expression and causes glucose intolerance in adult offspring. Journal of Clinical Investigation 101 2174-2181.

Nyirenda MJ, Welberg LA \& Seckl JR 2001 Programming hyperglycaemia in the rat through prenatal exposure to glucocorticoids - fetal effect or maternal influence? Journal of Endocrinology 170 653-660.

Padbury JF, Polk DH, Ervin MG, Berry LM, Ikegami M \& Jobe AH 1995 Postnatal cardiovascular and metabolic responses to a single intramuscular dose of betamethasone in fetal sheep born prematurely by cesarean section. Pediatric Research 38 709-715.

Pratt L, Magness RR, Phernetton T, Hendricks SK, Abbott DH \& Bird IM 1999 Repeated use of betamethasone in rabbits: effects of treatment variation on adrenal suppression, pulmonary maturation, and pregnancy outcome. American Journal of Obstetics and Gynecology 180 995-1005.

Rodnick KJ, Henriksen EJ, James DE \& Holloszy JO 1992a Exercise training, glucose transporters, and glucose transport in rat skeletal muscles. American Journal of Physiology 262 C9-C14.

Rodnick KJ, Piper RC, Slot JW \& James DE $1992 b$ Interaction of insulin and exercise on glucose transport in muscle. Diabetes Care 15 1679-1689.

Schiaffino S, Gorza L, Sartore S, Saggin L, Ausoni S, Vianello M, Gundersen K \& Lomo T 1989 Three myosin heavy chain isoforms in type 2 skeletal muscle fibres. Journal of Muscle Research and Cell Motility 10 197-205.

Schroeder RE, Doria-Medina CL, Das UG, Sivitz WI \& Devaskar SU 1997 Effect of maternal diabetes upon fetal rat myocardial and skeletal muscle glucose transporters. Pediatric Research 41 11-19.

Seckl JR \& Miller WL 1997 How safe is long-term prenatal glucocorticoid treatment? Journal of the American Medical Association 277 1077-1079.

Seckl JR, Benediktsson R, Lindsay RS \& Brown RW 1995 Placental 11 beta-hydroxysteroid dehydrogenase and the programming of hypertension. Journal of Steroid Biochemistry and Molecular Biology 55 447-455.

Sloboda DM, Newnham JP \& Challis JR 2000 Effects of repeated maternal betamethasone administration on growth and hypothalamic-pituitary-adrenal function of the ovine fetus at term. Journal of Endocrinology 165 79-91.

Stonestreet BS, Le E \& Berard DJ 1993 Circulatory and metabolic effects of beta-adrenergic blockade in the hyperinsulinemic ovine fetus. American Journal of Physiology 265 H1098-H1106.

Talmadge RJ \& Roy RR 1993 Electrophoretic separation of rat skeletal muscle myosin heavy-chain isoforms. Journal of Applied Physiology 75 2337-2340.

Thamotharan M, McKnight RA, Thamotharan S, Kao DJ \& Devaskar SU 2003 Aberrant insulin-induced GLUT 4 translocation predicts glucose intolerance in the offspring of a diabetic mother. American Journal of Physiology Endocrinology and Metabolism 284 E901-E914.

Thamotharan M, Shin BC, Suddirikku DT, Thamotharan S, Garg M \& Devaskar SU 2005 GLUT 4 expression and subcellular localization in the intrauterine growth-restricted adult rat female offspring. American Journal of Physiology Endocrinology and Metabolism 288 E935-E947.

Thorp JA, Jones AM, Hunt C \& Clark R 2001 The effect of multidose antenatal betamethasone on maternal and infant outcomes. American Journal of Obstetics and Gynecology 184 196-202.

Received in final form 3 February 2006 Accepted 12 February 2006 